\title{
Daur Ulang Air Buangan Menjadi Air Baku Dengan Sistem Filtrasi Di PT P (Industri Kertas)
}

\author{
Andika Munandar ${ }^{1 *}$, Vinda Avri ${ }^{2}$, Sillak Hasiany ${ }^{3}$ \\ ${ }^{1,2,3}$ Program Studi Teknik Lingkungan, Jurusan Teknologi Infrastruktur dan Kewilayahan, \\ Institut Teknologi Sumatera \\ Surel: ${ }^{1 *}$ andika.munandar@tl.itera.ac.id
}

\section{ABSTRAK}

Air buangan merupakan air dari pengolahan air limbah yang telah memenuhi baku mutu sebagai air buangan ke lingkungan, namun beberapa pabrik mengolah air buangan menjadi air baku untuk memenuhi kebutuhan air pada proses produksi. Proses produksi pabrik kertas berjalan secara kontiyu sehingga kebutuhan air sangat besar. Hal ini menjadi permasalahan karena untuk memenuhi kebutuhan air pabrik menggunakan air permukaan (sungai) dan peraturan tentang regulasi kualitas air. Oleh sebab itu pabrik kertas melakukan inovasi berupa penggunaan kembali air buangan dengan sistem filtrasi sehingga didapatkan kualitas air baku yang memenuhi kualitas air yang dapat digunakan untuk proses produksi. Hasil dari sistem filtrasi pada air buangan memiliki kondisi optimal 30 detik saat proses filtrasi dan menunjukkan penurunan sebesar TSS $67,21 \%$, COD $64,9 \%$, Kekeruhan $62,35 \%$ dan warna $79,96 \%$ yang menunjukkan telah memenuhi baku mutu dari perusahaan dan pemerintah.
\end{abstract}

\section{Kata kunci}

Air buangan,

Air baku,

Filtrasi,

Pengolahan.

\section{PENDAHULUAN}

Air buangan merupakan air dari pengolahan air limbah yang telah memenuhi baku mutu sebagai air buangan ke lingkungan, namun beberapa pabrik mengolah air buangan menjadi air baku untuk memenuhi kebutuhan air pada proses produksi $^{[1]}$. Proses produksi pabrik kertas berjalan secara kontiyu dan setiap proses membutuhkan air sehingga kebutuhan air sangat besar ${ }^{[2]}$. Hal ini menjadi permasalahan karena untuk memenuhi kebutuhan air pabrik menggunakan air permukaan (sungai) yang akan mengalami penurunan jumlah ketika musim kemarau, selain itu kualitas air harus memenuhi standar pabrik kertas agar didapatkan kualitas kertas yang baik ${ }^{[3]}$. Pengolahan air limbah didorong oleh adanya antisipasi perubahan regulasi kualitas air yang semakin ketat dan ketersediaan sumberdaya air semakin menipis yang adanya penekanan terhadap keperluan penggunaan air kembali ${ }^{[4]}$.

Kualitas air baku yang digunakan oleh pabrik kertas memenuhi standar dari pabrik kertas dan peraturan pemerintah RI No.82 Tahun 2001 tentang pengelolaan kualitas air dan pengendalian pecemaran air sehingga air tersebut dapat digunakan kembali, pengolahan air buangan menjadi air baku memiliki beberapa metode mulai dari yang sederhana hingga yang advance, metode digunakan berupa sistem yang sederhana seperti filtrasi disebabkan untuk tidak menaikkan biaya produksi dalam hal ini pengolahan air ${ }^{[5]}$. Filtrasi adalah proses pemisahan cairan dan padatan dengan cara melewatkan zat cair 
melalui media berpori atau bahan-bahan berpori untuk menyisihkan atau menghilangkan sebanyak-banyaknya butiranbutiran halus zat padat tersuspensi dari zat cair $^{[6]}$. Faktor yang mempengaruhi efisiensi penyaringan ada 4 (empat) yaitu:

1. Kualitas air baku, semakin baik kualitas air baku yang diolah maka akan baik pula hasil penyaringan yang diperoleh.

2. Suhu, Suhu yang baik yaitu antara 20$30^{\circ} \mathrm{C}$, temperatur akan mempengaruhi kecepatan reaksi-reaksi kimia.

3. Kecepatan Penyaringan, Pemisahan bahan-bahan tersuspensi dengan penyaringan tidak dipengaruhi oleh kecepatan penyaringan. Berbagai hasil penelitian menyatakan bahwa kecepatan penyaringan tidak mempengaruhi terhadap kualitas effluent. Kecepatan penyaringan lebih banyak terhadap masa operasi saringan.

4. Diameter butiran, secara umum kualitas effluent yang dihasilkan akan lebih baik bila lapisan saringan pasir terdiri dari butiran-butiran halus. Jika diameter butiran yang di gunakan kecil maka yang terbentuk juga kecil ${ }^{[7]}$.

Zat padat pada bahan filtrasi memiliki bentuk berpori sehingga dapat terjadi adsorpsi, adsorpsi merupakan fenomena yang terjadi pada permukaan. Adsorpsi secara umum didefinisikan sebagai akumulasi sejumlah molekul, ion atau atom yang terjadi pada batas antara dua fasa. Adsorpsi menyangkut akumulasi atau pemutusan substansi adsorbat pada adsorben dan hal ini dapat terjadi pada antar muka dua fasa ${ }^{[8]}$. Jenis adsorpsi dibagi menjadi dua jenis yaitu adsorpsi fisik dan adsorpsi kimia, hal ini berkaitan dengan kemampuan zat padat menjerap dan kemampuan menahan zat pengotor dalam rongga pori zat padat tersebut.

Oleh karena hal tersebut maka dilakukan penelitian tentang daur ulang air buangan dengan sistem filtrasi yang memiliki tujuan berupa mengetahui waktu optimal sistem filtrasi ketika air buangan menjadi air baku, dan mengetahui penurunan kualitas air buangan hasil sistem filtrasi berdasarkan peraturan pabrik kertas dan peraturan pemerintah.

\section{METODE PENELITIAN}

Penelitian ini dilakukan pada laboratorium PT X (industri kertas) selama 10 hari, penelitian ini dimulai dari pembuatan alat filtrasi dengan sistem aliran dari atas ke bawah menggunakan gaya gravitasi. Setelah alat filtrasi siap digunakan maka dilakukan kalibrasi dan dibuat kondisi alat filtrasi siap digunakan. Hal ini dikarenakan alat filtrasi berisi adsorben yang berupa padatan sehingga perlu dibuat kondisi basah terlebih dahulu sebelum digunakan agar tidak menganggu data penelitian yang disebabkan oleh pengotor ataupun lainnya pada adsorben. Penelitian ini menggunakan variasi laju aliran yaitu $0,3,30$, dan 60 detik dengan cara diatur kran pada pipa pengolahan sistem filtrasi dan menggunakan stop watch untuk melihat laju aliran.

\section{HASIL DAN PEMBAHASAN}

Pabrik kertas membutuhkan air dengan jumlah besar untuk proses produksi, hal ini tidak terpenuhi ketika musim kemarau dikarenakan air permukaan mengalami penyusutan sehingga perlu dilakukan inovasi untuk memenuhi kebutuhan air. Inovasi yang dilakukan berupa penggunaan kembali air buangan hasil pengolahan air limbah yang telah memenuhi baku mutu air buangan, oleh karena itu maka perlu dilihat kualitas air buangan.

Tabel 1. Kualitas Air buangan

\begin{tabular}{cccc}
\hline $\begin{array}{c}\text { TSS } \\
(\mathrm{mg} / \mathrm{L})\end{array}$ & $\begin{array}{c}\text { COD } \\
(\mathrm{mg} / \mathrm{L})\end{array}$ & $\begin{array}{c}\text { Kekeruhan } \\
(\mathrm{NTU})\end{array}$ & $\begin{array}{c}\text { Warna } \\
(\mathrm{TCU})\end{array}$ \\
\hline 121,90 & 292.20 & 170,30 & 198,76 \\
\hline
\end{tabular}

Berdasarkan data Tabel 1 terlihat kualitas air buangan dari beberapa parameter yang menjadi baku mutu air di pabrik $\mathrm{P}$ yang digunakan proses produksi dan peraturan pemerintah tentang kualitas air. Setelah mengetahui hal tersebut maka dilakukan pengolahan air buangan untuk menjadi air baku yang dapat digunakan pada proses produksi dengan sistem filtrasi. 


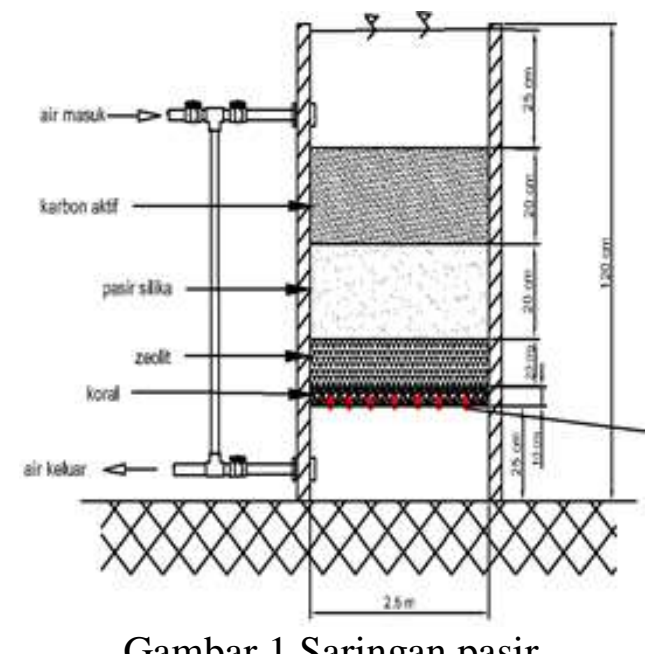

Gambar 1 Saringan pasir

Sistem filtrasi dapat dilihat pada gambar 1 yang di mulai dari air masuk sampai air keluar dan susunan dari saringan pasir. Saringan pasir menggunakan sistem gravitasi dan zat padat yang gunakan berupa karbon aktif hingga koral dengan berbagai ukuran, bentuk saringan pasir yang digunakan berdasarkan penelitian Setyobudiarso dan Yuwono $^{[9]}$ yang melakukan perancangan bangunan penjernih air limbah laundry. Selain itu ada penelitian yang dilakukan oleh Gultom $^{[10]}$ tentang media yang digunakan filtrasi dan menunjukkan bahwa media (bahan) filtrasi yang digunakan gambar 1 telah memenuhi kriteria. selanjutnya air buangan (tabel 1) diolah menggunakan saringan tersebut dengan menggunakan variabel berupa laju filtrasi dimulai dari 0,3 , 30, dan 60 detik.

Setelah dilakukan filtrasi maka dilanjutkan dengan pengujian dan pengambilan data sesuai dengan tabel 1, yang menunjukkan penurunan konsentrasi dari nilai COD dan TSS terlihat pada Gambar 2, penurunan konsentrasi COD dan TSS disebabkan terjadi proses penyaringan dan penjerapan oleh zat padat yang terdapat pada filter.

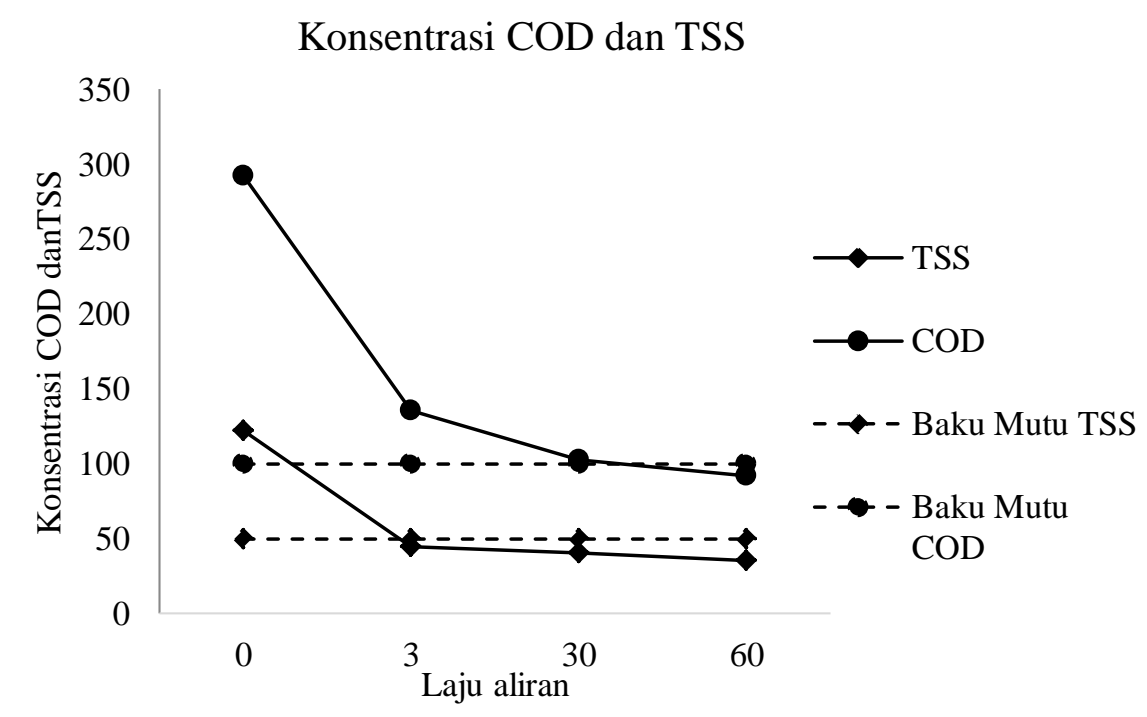

Gambar 2. Penurunan Konsentrasi COD dan TSS

Berdasarkan Gambar 2 bahwa laju filtrasi yang optimal pada detik ke 30, hal ini dikarenakan nilai COD dan TSS telah sesuai baku mutu dari pabrik dan peraturan pemerintah. hal ini diperkuat oleh penelitian Dewi dan Buchori ${ }^{[11]}$ yang menggunakan saringan pasir untuk mengolah air limbah dari industri tahu walaupun memiliki perbedaan waktu optimal yang disebabkan oleh perbedaan ketebalan dari saringan.
Selain itu dilakukan pengujian untuk mengetahui warna dan kekeruhan dari air hasil filtrasi yang terlihat pada Gambar 3 menunjukkan nilai dari warna dan kekeruhan yang merupakan parameter yang terdapat pada peraturan pemerintah dan digunakan oleh pabrik kertas sebagai standar air baku untuk proses produk. 
Kekeruhan dan warna

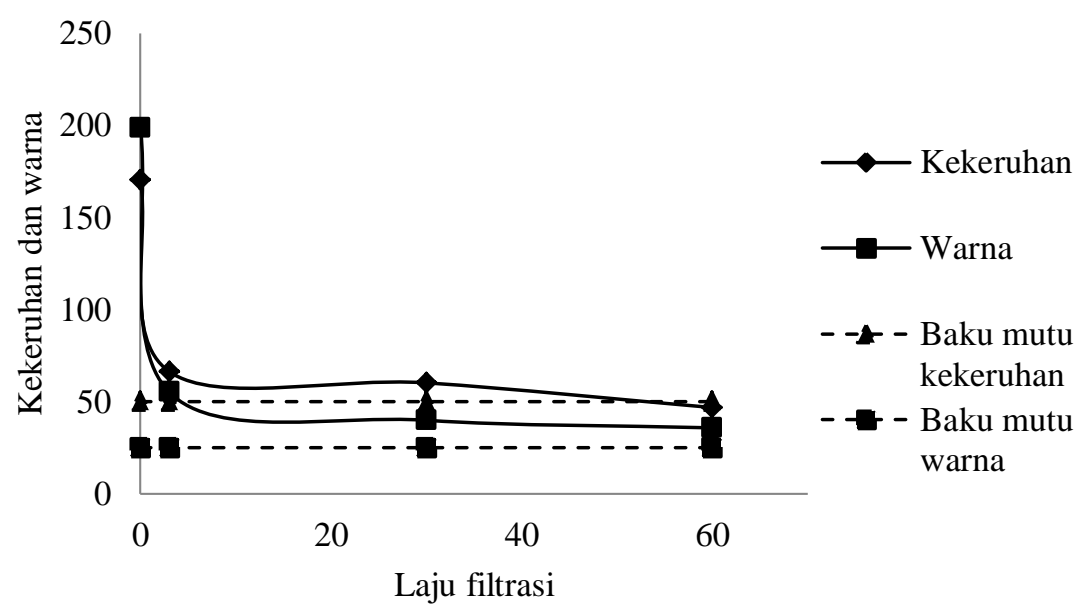

Gambar 3. Nilai kekeruhan dan warna

Berdasarkan dari kedua parameter tersebut hanya nilai warna yang berada di bawah standar baku mutu, sedangkan nilai kekeruhan masih di atas standar baku mutu air baku. Akan tetapi kedua parameter ini tidak memberikan pengaruh yang signifikan karena air baku hanya digunakan untuk proses produksi bukan untuk menjadi air konsumsi yang memiliki standar baku mutu yang lebih tinggi ${ }^{[2]}$.

Nilai kekeruhan dipengaruhi oleh zat pengotor yang terdapat pada air buangan karena diukur berdasarkan cahaya yang dapat melewati air dan kekeruhan dipengaruhi salah satunya dari adsroben (zat padat) karena adsroben masih terdapat pengotor pada poriporinya ataupun telah terlampau jenuh sehingga kemampuan dalam menyaring dan menjerap berkurang ${ }^{[12]}$. Hal ini diperkuat oleh penelitian Devi ${ }^{[13]}$ yang menunjukkan bahwa terjadi penurunan pada kekeruhan walaupun sistem alat filtrasi telah mengalami titik jenuh.

Setelah melihat hasil pada gambar 2 dan 3 maka perlu diketahui persentase dari penurunan dari keempat parameter tersebut yang dapat dilihat pada tabel 2 yang menunjukkan bahwa nilai penurunan dari keempat parameter melebihi dari 50\% yang menunjukkan bahwa sistem filtrasi dapat digunakan untuk mengolah air buangan menjadi air baku.
Tabel 2. Persentase penurunan dari keempat parameter

\begin{tabular}{ccccc}
\multicolumn{5}{c}{ parameter } \\
\hline $\begin{array}{c}\text { Filtrasi } \\
\text { dengan } \\
\text { kecepatan } \\
\text { flow }(\mathrm{t})\end{array}$ & $\begin{array}{c}\text { TSS } \\
(\%)\end{array}$ & $\begin{array}{c}\text { COD } \\
(\%)\end{array}$ & $\begin{array}{c}\text { Kekeruhan } \\
(\%)\end{array}$ & $\begin{array}{c}\text { Warna } \\
(\%)\end{array}$ \\
\hline 3 detik & 63,93 & 53,9 & 61,17 & 72,21 \\
30 detik & 67,21 & 64,9 & 62,35 & 79,96 \\
60 detik & 71,31 & 68,51 & 67,70 & 82,03 \\
\hline
\end{tabular}

Penelitian yang dilakukan oleh Rachmawan $^{[14]}$ menunjukkan penurunan nilai dari COD dan TSS yang lebih dari $50 \%$ pada limbah cair tahu. Sedangkan untuk kekeruhan dan warna diperkuat oleh penelitian yang dilakukan oleh Pamularsih ${ }^{[15]}$ yang menggunakan sistem filtrasi namun untuk air sungai yang akan digunakan menjadi air baku.

Berdasarkan hasil penelitian yang dilakukan dapat disimpulkan bahwa laju filtrasi yang optimal ialah pada 30 detik dan persentase penurunan untuk masing-masing parameter lebih dari $50 \%$.

\section{KESIMPULAN}

1. Laju filtrasi yang optimal selama 30 detik.

2. Persentase penurunan dari masing paremeter pada waktu optimal adalah TSS sebesar $67,21 \%$, COD sebesar 64,9 $\%$, kekeruhan sebesar $62,35 \%$, dan warna sebesar 79,96\%. 


\section{REFERENSI}

[1] Anggraini, A. N., Sugito, S., 2019, Peningkatan Kualitas Olahan Air Limbah Kawasan Industri Menggunakan Dual Filtrasi Membran Keramik, WAKTU, 17(02), 6-18.

[2] Putri, A. H., Hasibuan, N. H., \& Hawari, F. Y., 2019), Kajian Industri Pulp dan Kertas di Indonesia.

[3] Welasih, T., 2008, Penurunan BOD dan COD Limbah Industri Kertas dengan Air Laut Sebagai Koagulan, $J$. Rekayasa Perencanaan, 4(2).

[4] Mackenzie, L. D., 2010, Water and Wastewater Engineering: Design Principles and Practice, Mc Graw-Hill.

[5] Sugiharto, 2014, Dasar-Dasar Pengelolaan Air Limbah. Universitas Indonesia (UI-Press).

[6] Nasution, A. W., Putri, R. N., Mayendra, E., 2019, Mengkaji Karakteristik Pemakai Teknologi Pengolahan Air Bersih Di Indonesia.

[7] Quddus, R., 2014, Teknik pengolahan air bersih dengan sistem saringan pasir lambat (downflow) yang bersumber dari Sungai Musi, Journal of Civil and Environmental Engineering, 2(4).

[8] Tandy, E., Hasibuan, I. F., Harahap, H., 2012), Kemampuan Adsorben Limbah Lateks Karet Alam terhadap Minyak Pelumas dalam Air, Jurnal Teknik Kimia USU, 1(2), 34-38.

[9] Setyobudiarso, H., Yuwono, E., 2014, Rancang Bangun Alat Penjernih Air Limbah Cair Laundry Dengan Menggunakan Media Penyaring Kombinasi Pasir-Arang Aktif, Jurnal Neutrino: Jurnal Fisika Dan Aplikasinya.
[10] Gultom, S. O., Mess, T. N., Silamba, I., 2018, Pengaruh Penggunaan Beberapa Jenis Media Filtrasi Terhadap Kualitas Limbah Cair Ekstraksi Sagu (Metroxylon sp.), AGROINTEK: Jurnal Teknologi Industri Pertanian, 12(2), 81-90.

[11] Dewi, Y. S., Buchori, Y., 2016, Penurunan COD, TSS Pada Penyaringan Air Limbah Tahu Menggunakan Media Kombinasi Pasir Kuarsa, Karbon Aktif, Sekam Padi Dan Zeolit.

[12] Valentina, A. E., Miswadi, S. S., Latifah, L., 2013, Pemanfaatan Arang Eceng Gondok Dalam Menurunkan Kekeruhan, COD, BOD pada Air Sumur. Indonesian Journal of Chemical Science, 2(2).

[13] Devi, L. P. W. K., Putra, K. D., Putra, A. B., 2013, Efektifitas Pengolahan Air Effluent Menjadi Air Reklamasi Di Instalasi Pengolahan Air Limbah Suwung Denpasar Ditinjau Dari Kandungan Kekeruhan, Total zat Terlarut (TDS), dan Total zat Tersuspensi (TSS), Jurnal Kimia (Journal of Chemistry).

[14] Rachmawan, D., 2014, Pengaruh Ketebalan Zeolit dalam Metode Filtrasi untuk menurunkan Parameter Chemical Oxygen Demand (COD) dan Total Suspended Solid (TSS) pada Limbah Cair Industri Tahu, Universitas Diponegoro.

[15] Pamularsih, C., Choanji, D., Widiasa, I. N., 2013, Penyisihan Kekeruhan pada Sistem Pengolahan Air Sungai Tembalang dengan Teknologi Rapid Sand Filter, Jurnal Teknologi Kimia Dan Industri, 2(4), 48-54. 